\title{
PELATIHAN DIGITAL ENTREPRENEUR DI MASA PANDEMI COVID-19
}

\author{
Zulafwan', Gusrio Tendra² \\ ${ }^{12}$ AMIK "Tri Dharma", Pekanbaru, Indonesia \\ email : zulafwan91@gmail.com¹, gusriotendra@gmail.com²
}

\begin{abstract}
Abstrak: Digital Enterpreneur adalah istilah yang menggambarkan bagaimana kewirausahaan akan berubah, karena bisnis dan masyarakat terus ditransformasikan oleh teknologi digital. Kewirausahaan digital menyoroti perubahan dalam praktik wirausaha, teori, dan pendidikan. Kewirausahaan digital mencakup segala sesuatu yang baru dalam hal tentang kewirausahaan di dunia digital. Hal-hal yang menjadi perhatian dalam berwirausaha dalam dunia digital antara lain ialah bagaimana cara baru mendapatkan ketertarikan pelanggan terhadap usaha yang dibangun, bagaimana cara baru dalam merancang, menawarkan produk, dan memberikan layanan yang terbaik, bagaimana cara baru menghasilkan pendapatan, dan mengurangi biaya, peluang baru untuk berkolaborasi dengan platform dan mitra dan sumber peluang, resiko, serta keunggulan kompetitif baru. Pelatihan ini dilaksanakan oleh Lembaga Penelitian dan Pengabdian Masyarakat (LPPM) AMIK "Tri Dharma" Pekanbaru, hal ini bertujuan untuk memberikan pengetahuan mengenai, jenis usaha, peluang usaha, dan cara yang digunakan untuk memulai digital entrepreneur pada masa pandemi COVID-19. Adapun materi yang diberikan terkait pengertian digital entrepreneur, jenisnya dan bagaimana cara memulainya. Pelatihan ini dilaksanakan secara daring menggunakan platform video conference zoom cloud meeting, waktu pelatihan satu hari dengan peserta terdiri dari mahasiswa, siswa SMK dan SMA serta masyarakat umum dilingkungan kota Pekanbaru. Berdasarkan kegiatan yang dilakukan peserta sangat antusias dalam mengikuti pelatihan, dimana hal tersebut dibuktikan dengan banyaknya pertanyaan-pertanyaan yang disampaikan oleh perserta kepada nara sumber berdasarkan materi yang di sampaikan. Hasil ahir dari pelatihan ini diharapkan para peserta dapat mengetahui apa itu digital entrepreneur, bagaimana memulainya, dan nantinya dapat memulai untuk dapat membuka usaha sendiri dibidang teknologi informasi.
\end{abstract}

Kata Kunci: Digital, Entrepreneur, Pandemi COVID-19

Abstract: Digital Entrepreneur is a term that describes how entrepreneurship will change, as business and society continue to be transformed by digital technology. Digital entrepreneurship highlights changes in entrepreneurial practice, theory and education. Digital entrepreneurship includes everything that is new when it comes to entrepreneurship in the digital world. Things that are of concern in entrepreneurship in the digital world include new ways to get customer interest in the business being built, new ways to design and offer products, and provide the best service, new ways to generate revenue, and reduce costs, New opportunities to collaborate with platforms and partners and New sources of opportunities, risks and competitive advantages. This training was carried out by the Research and Community Service Institute (LPPM) AMIK "Tri Dharma" Pekanbaru, it aims to provide knowledge about the types of businesses, business opportunities, and methods used to start digital entrepreneurs during the COVID-19 pandemic. The material provided is related to the definition of digital entrepreneur, its types and how to get started. This training was carried out online using a video conference platform zoom cloud meeting, one day training time with participants consisting of students, vocational and high school students and the general public in the city of Pekanbaru. Based on the activities carried out, the participants were very enthusiastic in participating in the training, where this was evidenced by the many questions submitted by the participants to the resource persons based on the material presented. The end result of this training is that it is hoped that the participants will be able to know what a digital entrepreneur is, how to start it, and later can start to open their own business in the field of information technology.

Keywords: Digital, Entrepreneur, Pandemic, COVID-19 


\section{Pendahuluan}

Pada masa pandemi COVID-19 ini semua kalangan masyarakat di seluruh dunia terkena dampak yang menyebabkan banyaknya perusahaan harus memberhentikan karyawan secara sepihak dikarenakan pemberlakukan pembatasan sekala besar yang menyebabkan perusahakan, toko, maupun usaha lainnya berhenti berproduksi. Hal ini tentunya menyebabkan setiap orang harus berfikir keras bagaimana cara yang akan digunakan untuk menghasilkan uang dalam bertahan hidup pada masa COVID-19.

Pengangguran dan kemiskinan menjadi ancaman yang besar bagi pemerintah khususnya pemerintah Indonesia. Berdasarkan data yang dihimpun oleh Trading Economics (2020) bahwa tingkat pengangguran di Indonesia berada pada posisi ke 104 di dunia dengan persentase 5,28\% per September 2019 dari 181 negara (Hendarsyah, 2020).

Banyaknya bantuan yang disalurkan oleh pemerintah guna membantu memecahkan masalah tersebut belum sepenuhnya dapat teratasi dengan tepat. Tentu masyarakat tidak boleh hanya diam dalam mengahadapi hal tersebut, setiap individu memiliki tanggung jawab dan kebutuhan tersendiri oleh karena itu membangun usaha adalah solusi yang paling tepat untuk membantu mengatasi masalah tersebut pada masa COVID-19 ini.

Saat ini fenomena perkembangan ekonomi digital di Indonesia memiliki peluang yang sangat menjanjikan di masa depan. Hal itu terlihat dari masifnya inovasi pelaku ekonomi digital dalam melebarkan bisnisnya. Sikap optimisme akan pergerakan ekonomi digital dalam beberapa tahun mendatang, bukan mustahil wirausaha muda baru akan terus lahir dan siap berkompetisi sehingga diharapkan dapat menggairahkan roda ekonomi tanah air (Hardiyanto, 2018). Digitalisasi terhadap dunia usaha dan dunia industri baik produksi maupun jasa sudah menunjukan strategi dalam mengintegrasikan semua sistem perusahaan baik kecil maupun besar (Putri, Yudhanegara, dan Fadilah, 2021).

Kewirausahaan atau Entrepreneur adalah penerapan kreativitas dan keinovasian untuk memecahkan permasalahan dan upaya memanfaatkan peluang-peluang yang dihadapi orang setiap hari. Dari pengertian ini, terlihat bahwa seorang entrepreneur harus memiliki kreativitas dan inovasi supaya bisa mengelola suatu usaha yang telah dibangun agar dilakukan dengan tepat dan benar (Nanda, dan Farida, 2018).

Entrepreneurship menjadi jalan yang paling efektif di tengah himpitan ekonomi yang semakin besar dan lapangan pekerjaan yang semakin sempit untuk membangkitkan kembali kehidupan perekonomian masyarakat. Menurut David Mc Clelland, suatu negara dapat menjadi makmur jika sedikitnya memiliki 2\% entrepreneurship dari jumlah penduduknya (Margahana, dan Triyanto, 2019).

Peranan UMKM (Usaha Mikro, Kecil dan Menengah) pada pertumbuhan ekonomi di Indonesia sudah tidak dapat dipungkiri lagi. UMKM telah memberikan kontribusi yang cukup besar, berdasarkan data tahun 2017 menunjukkan kontribusi UMKM terhadap PDB nasional adalah sebesar Rp 7.005.950 milyar atau sekitar 62,57\% dari total PDB (LEI, 2018) (Utomo, Cahyaningrum, Hasyim, 2019). 
Pada saat ini pelaku wirausahan tidak hanya digeluti orang tua atau dewasa, bahkan sekarang banyak anak muda yang mengeluti dunia Entrepreneur terutama Entrepreneur digital. Digital Enterpreneur mencakup segala sesuatu yang baru dalam hal tentang kewirausahaan di dunia digital, termasuk cara baru menemukan pelanggan untuk usaha wirausaha, cara-cara baru dalam merancang dan menawarkan produk, dan layanan, cara baru menghasilkan pendapatan, dan mengurangi biaya, peluang baru untuk berkolaborasi dengan platform dan mitra dan Sumber peluang, risiko, dan keunggulan kompetitif baru.

Generasi milenial sangat lekat sekali dengan teknologi informasi. Mereka terbiasa dengan internet dan gadget. Namun banyak generasi milenial yang tidak memanfaatkan alat teknologi tersebut untuk hal-hal positif khususnya usaha atau bisnis yang menghasilkan. Fenomena digital entrepreneurship memiliki peluang yang lebar di masa yang akan datang dan itu harus menjadi perhatian kita semua. Beberapa perusahaan sukses berkat pemanfaatan teknologi informasi seperti grab, gojek, bukalapak, tokopedia, olx, dan lain lain (Gunawan, 2020).

Kegiatan pelatihan digital enterpreneur yang dilakukan ini dilatarbelakangi oleh wabah pandemi COVID-19 yang melanda di negeri ini, dengan pelatihan yang dilakukan diharapkan masyarakat mendapatkan masukan berupa pengetahuan yang dapat digunakan untuk mulai memulai mendapatkan ide dan tujuan dalam membangun usaha melalui dunia digital. Dunia digital sangat luas mampu menjangkau masyarakat yang terbatas dengan jarak, serta mempermudah komunikasi dengan berbagai media seperti halnya sosial media, marketplace, dan start upyang menyediakan lokasi dan tempat usaha secara gratis. Bahkan tanpa menggunakan modal untuk memulai dalam membangun usaha, yang terpenting ialah kemauan dan semangat yang tinggi untuk memulai hal tersebut.

\section{Metode}

Metode pelaksanaan kegiatan ini melalui webinar daring, peserta dari khalayak umum yang terdiri dari mahasiswa, guru dan siswa. Adapun pemateri berjumlah 2 orang yang merupakan dosen AMIK Tri Dharma Pekanbaru yaitu Zulafwan, S.Kom, M.Kom dan Gusrio Tendra, S.Kom, M.Kom. selain pemateri terdapat panitia yang bertugas untuk mensukseskan acara yang terdiri dari moderator dan operator yang merupakan karyawan dari AMIK Tri Dharma Pekanbaru.

Materi yang disampaikan pada kegiatan meliputi konsep dasar dari Digital Enterpreneur, jenisnya beserta cara agar menjadi Digital Enterpreneur. Pada kesempatan tersebut pemateri juga mencontohkan Digital Enterpreneur yang sudah dilakukan oleh pemateri yaitu mengelola toko online dan memiliki aplikasi android di playstore yang bisa mendatangkan uang.Adapaun rangkaian kegiatan dari awal sampai akhir dapat dilihat pada gambar 1 di bawah ini. 


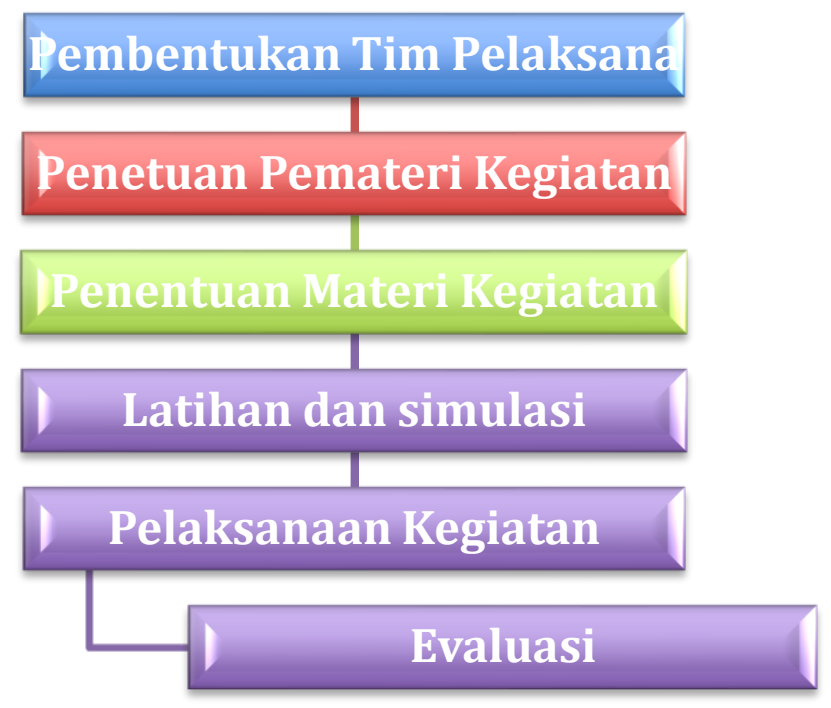

Gambar 1. Alur Kegiatan Pelatihan Digital Enterpreneur

Dalam menyebarluaskan informasi kegiatan, panitia menyiapkan flyer yang berisi informasi jadwal kegiatan, pemateri dan metode kegiatan melalui sosial media kampus dan media sosial masing-masing panitia, flyer juga diberikan kepada pihak sekolah di provinsi Riau yang menjalin kerja sama dengan kampus AMIK "Tri Dharma" Pekanbaru. flyer merupakan selembaran kertas yang berisi tulisan dengan kalimat-kalimat yang singkat, padat, mudah dimengerti, dan gambar-gambar yangsederhana (Prasanti, dan Fuady, 2018). Adapun bentuk flyer dari kegiatan dapat dilihat dari gambar 2 di bawah ini.

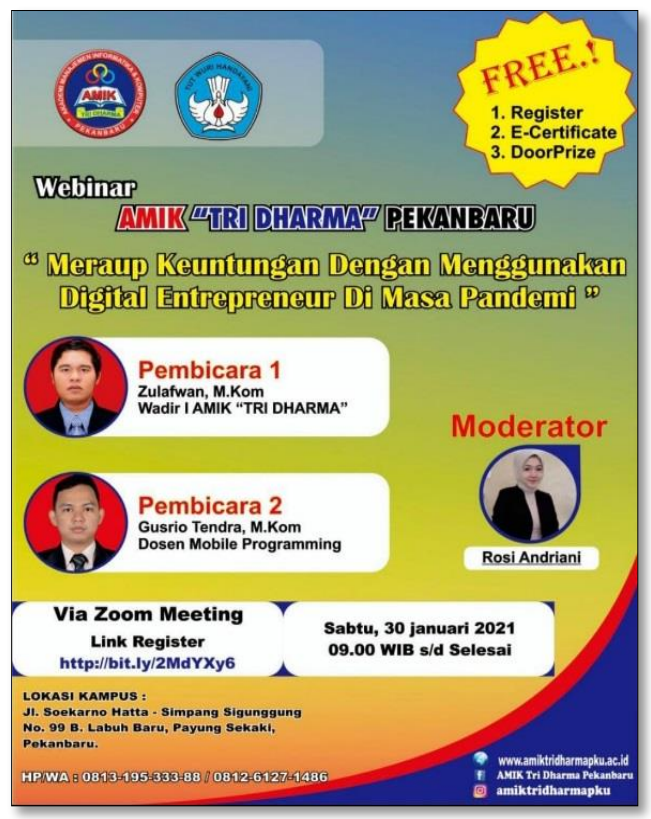

Gambar 2. Flyer Kegiatan Digital Enterpreneur

\section{Hasil dan Pembahasan}

Pada bagian ini panitia dan tim pelaksana telah menyiapkan semua kebutuhan untuk palaksanaan kegiatan, pelatihan dilakukan secara daring menggunakan video conference 
dikarenakan pada saat dilakukannya kegiatan pelatihan ini pemerintah masih menerapkannya pembatasan dalam mengumpulkan orang banyak, namun meskipun dilakukan secara daring, kegiatan dapat berjalan dengan baik.

Kegiatan diawali dengan pembukaan oleh moderator, lalu sepatah kata dari Direktur AMIK "Tri Dharma" Pekanbaru sekaligus membuka secara resmi kegiatan. Setelah itu kegiatan dilanjutkan dengan pemaparan dari pemateri pertama, dilajutkan dengan diskusi tanya jawab. Setelah pemateri pertama selesai, dilanjutkan dengan pemaparan pemateri kedua dan diakhiri dengan sesi tanya jawab.

Peserta yang mengikuti kegiatan pelatihan diberikan absensi dengan menggunakan media google form untuk mempermudah panitia dalam membuat sertifikat pelatihan yang akan diberikan dan dikirimkan melalui email masing-masing peserta secara digital. Sertifikat diberikan apabila setiap peserta telah mengisi formulir pendaftaran yang disediakan pada flyer, serta hadir dan mengikuti pelatihan dari awal kegiatan hingga berakhirnya kegiatan pelatihan. Materi kegiatan juga akan di berikan melalui share dokumen pada messanger aplikasi Zoom Meeting. Zoom Meeting sendiri merupakan sebuah media pembelajaran menggunakan video (Haqien, dan Rahman, 2020). Aplikasi Zoom Cloud Meeting merupakan salah satu media e-learning yang digunakan dengan tujuan untuk mencapai pemahaman mahasiswa di tengah pandemi (Putri $\mathrm{H}$, dan Wulandari, 2020).

Selain itu peserta juga dapat mendownload document secara individu. Kegiatan terakhir adalah dokumentasi dan foto bersama pemateri dan peserta. Berikut beberapa tangkapan layar dari kegitan yang dapat dilihat pada gambar 3 dibawah ini.
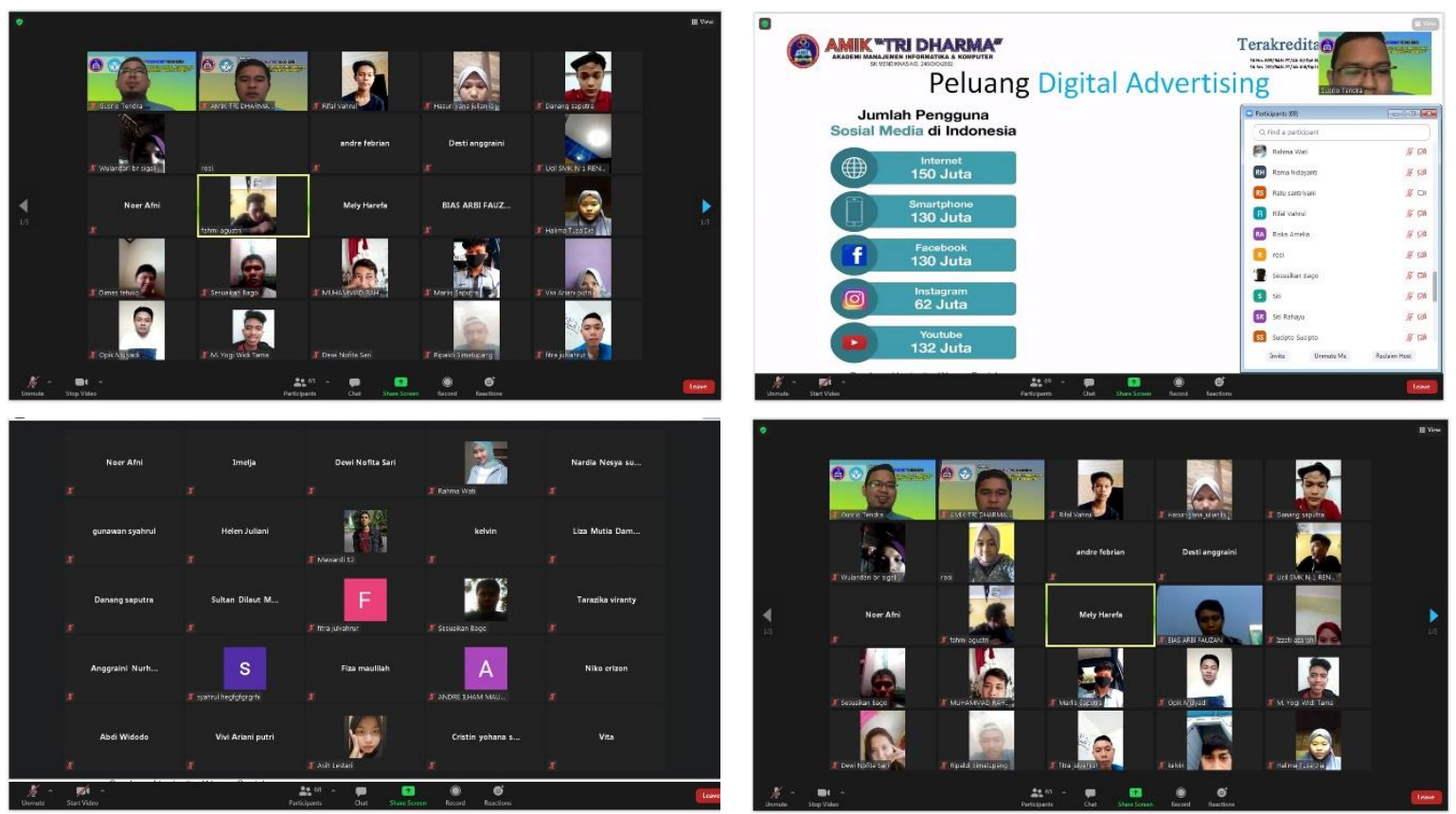

Gambar 3. Dokumentasi Kegiatan 


\section{Kesimpulan}

Kesimpulan yang dapat ditarik penulis setelah melakukan kegiatan ini adalah Digital Enterpreneur masih menjadi sebuah informasi baru bagi peserta sehinnga peserta terlihat tertarik dan antusias untuk bertanya lebih dalam lagi ke pemateri terkait Digital Enterpreneur, selain itu beberapa peserta terlihat sudah memikirkan ide dan memilih jenis Digital Enterpreneur yang akan digelutinya

Saran dari beberapa peserta adalah kegiatan serupa perlu dilaksanakan kembali guna menggali lebih dalam lagi ilmu yang didapatkan dan bisa langsung mempraktekkannya nantinya.

\section{Ucapan Terima Kasih}

Penulis mengucapkan Terima kasih yang sebesar-besarnya kepada AMIK "Tri Dharma" Pekanbaru dan seluruh sivitas beserta panitia yang telah berpartisipasi serta telah mendukung tim untuk dapat melaksanakan kegiatan ini dengan baik sejak awal hingga selesai. Selain itu kepada para peserta yang tidak bisa kami sebutkan satu persatu juga kami ucapkan terima kasih atas waktu dan kesempatan yang telah disediakan untuk kita, semoga apa yang telah kita sampaikan menjadi ilmu yang bermanfaat untuk pemateri dan untuk para peserta.

\section{Daftar Pustaka}

Gunawan, Ahmad. 2020. "Pelatihan Digital Entrepreneurship Mewujudkan Generasi Milenial Berjiwa Wirausaha Di Sekolah SMA Desa Karangasih Cikarang." Jurnal Adbimas Kartika Wijayakusuma 1: 38-45. https://journal.unjani.ac.id/index.php/jkwk/article/view/11/3.

Haqien, Danin, and Aqiilah Afiifadiyah Rahman. 2020. "Pemanfaatan Zoom Meeting Untuk Proses Pembelajaran Pada Masa Pandemi Covid-19." Jurnal SAP (Sususnan Artikel Pendidikan) 5(1): 51-56.

Hardiyanto, Lutfi. 2018. "Motivasi Mahasiswa Menjadi Start Up Digital Entrepreneur (Technopreneur)." Jurnal IImu Pendidikan (JIP) STKIP Kusuma Negara Jakarta 10: 115. http://jurnal.stkipkusumanegara.ac.id/index.php/jip/article/view/9.

Hendarsyah, Decky. 2020. "Pemasaran Digital Dalam Kewirausahaan." Jurnal I/miah Ekonomi Kita 9(1): 25-43. https://ejournal.stiesyariahbengkalis.ac.id/index.php/iqtishaduna/article/view/209.

Margahana, Helisa, and Eko Triyanto. 2019. "Membangun Tradisi Entrepreneurship Pada Masyarakat." Jurnal Edukomika 3(2): 300-309.

Nanda, Alfina Ari, and Lea Emilia Farida. 2018. "Strategi Pengembangan Digital Entrepreneur Di Kota Banjarmasin Dalam Menghadapi Era Asean-China Free Trade Agreement." Prodising Seminar Nasional ASBIS 6014: 81-90. http://eprosiding.poliban.ac.id/index.php/asbis/article/view/290. 
Prasanti, Ditha, and Ikhsan Fuady. 2018. "Pemanfaatan Media Komunikasi Dalam Penyebaran Informasi Kesehatan Kepada Masyarakat." Jurnal Reformasi 8: 8-14.

Putri H, Radisya Eka, and Tine Agustin Wulandari. 2020. "Pemanfaatan Aplikasi Zoom Cloud Meeting Sebagai Media E-Learning Dalam Mencapai Pemahaman Mahasiswa Ditengah Pandemi Covid-19." Jurnal Common 4: 171-90.

Putri, Pandena Kicky Basuki, Darmawan Yudhanegara, and Rizki Fadilah. 2021. "Digitalisasi Keuangan Ukm." Jurnal Riset Enterpreneurship 4(2): 4-10.

Utomo, Mohamad Nur, Widyastuti Cahyaningrum, and Budi Hasyim. 2019. "Karakteristik Entrepreneur Dan Kesuksesan Bisnis Umkm Di Kota Tarakan." Jurnal Borneo Humaniora: 1-7. 